\title{
Modified Houdek vault applicator for high-dose-rate brachytherapy: a technical report and case series
}

\author{
Revathy Krishnamurthy, MD!, Lavanya Gurram, MD!, Yogesh Ghadi, MSc, DipRP², Dheera Aravindhan, MSc, DipRP2, \\ Libin Scaria, MSc, DipRP22, Satish Kohle, MSc, PGDRTT22, Sudarshan Kadam, MSc, PGDRTT22, Supriya Chopra, MD, DNB!' \\ Umesh Mahantshetty, MD, DNB!3
}

'Department of Radiation Oncology, Tata Memorial Hospital, Homi Bhabha National Institute, Mumbai, India, ${ }^{2}$ Department of Medical Physics, Tata Memorial Hospital, Homi Bhabha National Institute, Mumbai, India, ${ }^{3}$ Homi Bhabha Cancer Hospital and Research Centre, Visakhapatnam, India

\begin{abstract}
Purpose: Treatment of isolated post-surgical vault recurrence of cervical and endometrial cancers in previously unirradiated patients includes external beam radiotherapy (EBRT) \pm concomitant chemotherapy, followed by brachytherapy (BT) boost. Supra-vaginal component of vault disease often requires interstitial BT for optimal dose coverage. We describe technical details and preliminary case series using modified Houdek vault applicator (MHVA) developed at our institution for limited intra-cavitary plus interstitial high-dose-rate (HDR) vault BT.

Material and methods: Nineteen patients with vaginal vault recurrences received BT boost with MHVA between October 2015 and May 2018. All underwent BT application and CT-based BT planning after completion of EBRT \pm concomitant chemotherapy.

Results: Median EQD $\mathrm{ED}_{2}$ BT dose in patients with carcinoma cervix recurrence $(n=15, \alpha / \beta=10)$ was $18.8 \mathrm{~Gy}$, and in those with endometrial cancer recurrence was $22.08 \mathrm{~Gy}(n=4, \alpha / \beta=4.5)$. Median total $\mathrm{EQD}_{2}$ was $68.8 \mathrm{~Gy}$ and $72.08 \mathrm{~Gy}$, respectively. Mean $2 \mathrm{cc}$ of bladder, rectum, and sigmoid EBRT + BT doses $\left(\mathrm{EQD}_{2}, \alpha / \beta=3\right)$ were $65.38 \mathrm{~Gy}( \pm 7.76), 63.37 \mathrm{~Gy}$ $( \pm 5.52)$, and 57.04 Gy $( \pm 4.45)$, respectively. At 6-8 weeks, 17 patients showed complete response $(\mathrm{CR})$. With median follow-up of 20.5 months, 2-year overall survival was 95\% (95\% CI: 85.2-100.0\%), and 2-year progression-free survival was $79.4 \%$ (95\% CI: 61.0-97.8\%). Late toxicities seen were grade 2 proctitis in 1 patient, grade 1 proctitis in 5, grade 2 urethritis in 1, grade 3 cystitis in 1, and recto-vaginal fistula in 1 patient (with disease controlled). Recurrence rate was 6.7 times higher in patients with post-EBRT disease greater than $10 \mathrm{~mm}(p=0.01)$.

Conclusions: MHVA is a simple solution for intra-cavitary and interstitial HDR-BT boost in isolated vault cancers post-surgery, achieving acceptable dosimetric parameters. Preliminary clinical outcomes and late toxicities are satisfactory.

Key words: vaginal vault, brachytherapy, intra-cavity radiotherapy, interstitial radiotherapy.

\section{Purpose}

Isolated vaginal vault recurrences of cervical and endometrial cancers post-surgery are commonly encountered in clinics [1,2]. The 2-year recurrence rate reported following primary surgery is $10-20 \%$ in patients with stage IBIIA node negative cervical tumors and up to $70 \%$ in more advanced stages without adjuvant therapy [1]. Recurrence rate in women with early endometrial cancers is reported as approximately $6-12 \%$ [3]. As high as $50-70 \%$ of patients are symptomatic at the time of recurrence, with vaginal bleeding being the most common symptom, followed by hematuria, hematochezia, decreased appetite, weight loss, and abdominal or back pain [4].
The standard treatment for isolated vaginal vault recurrences of cervical and endometrial cancers in patients who have not received prior pelvic radiotherapy is radio(chemo)therapy including brachytherapy (BT) boost [5-7]. Radiation therapy would include standard external beam pelvic fields followed by BT boost, depending on the residual disease. Vault BT is also commonly employed as a sole therapy for previously irradiated cases, with an acceptable disease-free interval to account for normal tissue toxicity [8]. The advantage of BT is that it can deliver a high-dose of irradiation to a small target volume, and therefore reduce the rate of complications. BT boost is challenging and depends on the residual disease and vault thickness [9].
Address for correspondence: Dr Lavanya Gurram, Assoc. Prof., Department of Radiation Oncology, Tata Memorial Hospital, Homi Bhabha National Institute, Mumbai, India, phone: +91 22241 77033, ๑ e-mail: naidu.lavanya@gmail.com
Received: 08.05 .2021 Accepted: 06.11.2021 Published: 30.12 .2021 
Commonly used intracavitary applicators for vault brachytherapy are single-channel cylinder applicator, with central vaginal source (CVS), multichannel cylinder applicator, with surface intra-vaginal applicator (SIVA), vaginal ovoids, and Houdek vault ring applicator [10-12]. Vault disease may have a supra-vaginal component, which cannot be treated adequately with a simple intracavitary vault BT. These case scenarios that require using interstitial BT [13]. Classical interstitial approach is to use perineal templates, such as Martinez universal perineal interstitial template (MUPIT), Syed-Neblett, and Benidorm templates [14]. The implantation process for these templates is complex, requiring expertise and a long learning curve.

We attempted a minor adaptation in an existing intracavitary ring applicator of the vault (Houdek applicator) by fitting an acrylic cap over the ring: the 'Modified Houdek Vault Applicator' (MHVA). In addition to a central hole for the central tandem, concentric arrays of holes were drilled on the cap for insertion of straight needles, as shown in Figure 1. After physics commissioning and dosimetric review, we tested for clinical utility of the applicator. The assessment of technical feasibility, dosimetric parameters, and preliminary clinical outcome constitute for the basis of this report.

\section{Material and methods}

\section{Description of the applicator}

The modified Houdek vault applicator has the following components:

1. Steel vault ring, available with outer diameters of $26 \mathrm{~mm}, 30 \mathrm{~mm}$, and $34 \mathrm{~mm}$.

2. Steel central tandem, $0 \mathrm{~mm}$ in length.

3. Acrylic (tissue inert material) cap to be fitted over the ring, with central hole for central tandem and concentric array of holes for straight needles. The inner circle has 8 equidistant holes and the outer circle has 20 . Customized caps are available for all ring diameters, with inner diameters of $26 \mathrm{~mm}, 30 \mathrm{~mm}$, and $34 \mathrm{~mm}$.

4. Stainless steel needles: 18 gauge, $20 \mathrm{~cm}$ length.

\section{Pre-implant planning}

Following completion of the pre-determined external beam radiotherapy (EBRT) dose, the patient with vault disease is assessed under anesthesia for residual disease. This is supplemented by cross-sectional imaging. As per ABS guidelines, any residual disease $>5 \mathrm{~mm}$ must be treated with interstitial brachytherapy [5]. In case of a residual disease with palpable nodularity at the vaginal vault extending superiorly, and with lateral extent within $20 \mathrm{~mm}$ from midline, MHVA may be useful. The diameter and length of the vault is noted and the disease is mapped on a clinical diagram. Based on clinical examination, disease mapping at diagnosis and at brachytherapy, a preliminary decision regarding the optimum needle positions and ring size is taken. The patient is admitted one day prior to procedure, with ability for general anesthesia confirmed, and recent blood profile, including a complete blood count, renal and liver function tests, serum electrolytes checked. Preparation of the patient is ensured, including local hygiene, bowel cleansing, and 4-6 hours fasting prior to BT procedure, with mild sedatives given if needed.

\section{BT implantation procedure}

The procedure has to be performed under general/ spinal anesthesia. The patient, after induction, is made to lie down in a lithotomy position. The parts are cleaned and draped, and a Foley's catheter inflated with a $7 \mathrm{ml}$ saline is inserted. The residual disease is demarcated using silver markers implanted into tissues. Vault diameter is confirmed and applicator size is chosen. Short central tandem is fixed to the ring and secured with a screw. An acrylic cap is then fitted over the ring. Straight stainless-steel needles are positioned in the holes of the cap, as determined during pre-planning. The assembled applicator is introduced into the vault such that the acrylic cap easily fits into the vault. The needles are then pushed into the vault to a distance as decided based on cross-sectional imaging, ensuring that the cap is not pushed away from the top of the vault. Intra-operative imaging in the form of trans-abdominal and/or transvaginal ultrasound is used on a case-by-case basis. The vault is then packed with betadine-soaked gauze, and the entire assembly secured with a perineal bandage. After recovery from anesthesia, a planning CT scan is taken with applicator in situ, with standard slice thickness of $2.5 \mathrm{~mm}$.

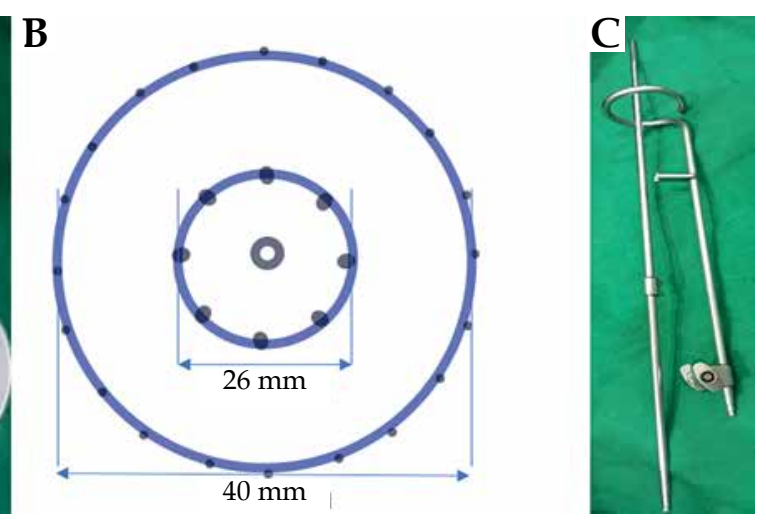

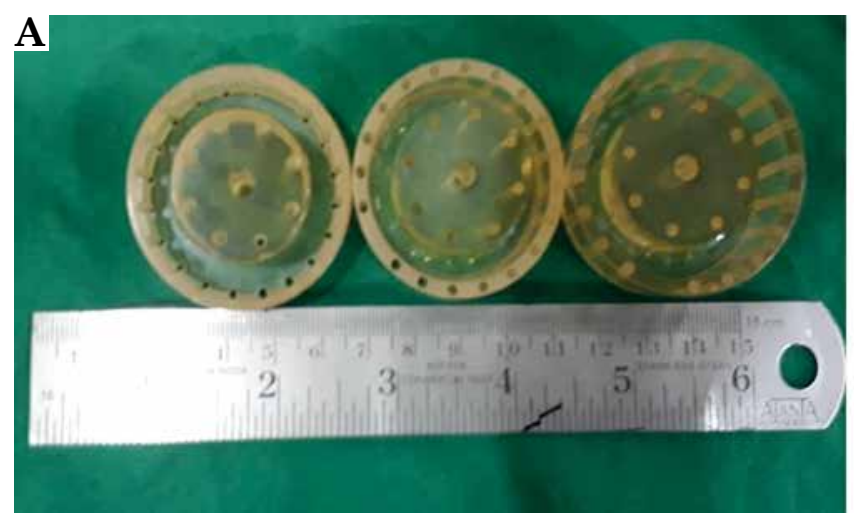

Fig. 1. A) Acrylic caps, B) Schematic diagram of a $26 \mathrm{~mm}$ acrylic cap, C) Ring and central tandem 


\section{Organs at risk (OARs) delineation}

The urinary bladder, ano-rectum, and sigmoid are delineated on the planning CT scan.

\section{Dose prescription and biological model for dose summation}

Dose prescription is decided based on EBRT dose received and the indication of therapy. Commonly used prescription after a whole pelvis EBRT to a dose of $50 \mathrm{~Gy} / 25 \mathrm{fx}$. is $4 \mathrm{~Gy} \times 4 \mathrm{fx}$. delivered twice a day. $\mathrm{EQD}_{2}$ (equieffective dose in $2 \mathrm{~Gy}$ ) is calculated using the following formula: $\mathrm{EQD}_{2}=\mathrm{D} \times([\mathrm{d}+(\alpha / \beta)] /[2+(\alpha / \beta)])$, where $\mathrm{D}$ is total dose given in $\mathrm{Gy}, \mathrm{d}$ is dose per fraction in Gy, and $\alpha / \beta$ is dose, at which linear and quadratic components of cell kill are equal [15]. $\alpha / \beta$ ratio of 3 and 10 are considered for normal tissue and tumor, respectively for cervical cancers, and 4.5 for a tumor in endometrial cancers $[16,17]$. The aim is to deliver a total dose of $70 \mathrm{~Gy}$ $\mathrm{EQD}_{2}(\mathrm{EBRT}+\mathrm{BT})$. Dose escalation can be considered in the presence of gross residual disease post-EBRT.

\section{Treatment planning}

Planning procedure done on Oncentra treatment planning software (versions 4.3 and 4.5 ) is explained below. Firstly, reconstructions of ring (offset, $7 \mathrm{~mm}$ ), short tandem (offset, $7 \mathrm{~mm}$ ), and needles (offset, $9 \mathrm{~mm}$ ) are carried out. A basic intracavitary plan is generated with the tandem and ring. Normalization is performed at two points in the central vertical plane of the applicator, $10 \mathrm{~mm}$ superior, and $15-20 \mathrm{~mm}$ lateral to the surface of the ring. Ring dwell weights are reduced to $70 \%$ to account for the short tandem length. A second plan for the interstitial component is generated with the needles, normalized to the basal points, following Paris system rules. Dwell weights are set at 10\% of the tandem dwell weights acquired in the first plan. The above 2 plans are then merged to create a composite plan (Figure 2). Manual dwell weight or graphical optimization can be done based on the assessment for adequate coverage of the residual disease. The silver markers placed at the time of implantation should be used as a guide for plan evaluation completed using visual inspection of isodoses.

\section{Treatment delivery and applicator removal}

Treatment is generally delivered with a 2 daily fractions, with two fractions at least 6 hours apart. The patient is kept admitted overnight for the fractions to be delivered on the second day. Adequate analgesia is ensured and the patient is kept on a liquid diet, with a Foley's catheter and flatus tube in situ. Care must be taken to prevent displacement of the applicator. After delivery of the last planned fraction, the applicator is removed under adequate analgesia and asepsis. The patient is discharged after passing urine and stools uneventfully. The patient is prescribed oral analgesics and antibiotics for one week.

\section{Follow-up}

Response assessment is done at 6 weeks after the procedure by clinical examination. Imaging in the form of CT abdomen + pelvis or FDG-PET scan is performed if local, regional, or distant disease recurrence is suspected clinically. Late toxicities are assessed using Radiotherapy Oncology Group (RTOG) toxicity scale [18].

\section{Results}

Nineteen patients (15 with primary cervical cancer and 4 with primary endometrial cancer) presenting with vaginal vault recurrences underwent BT using MHVA at our institute between May 2016 and December 2018. None of the patients had received prior radiotherapy. All the patients underwent BT application and CT-based BT planning after completion of EBRT. Concomitant chemotherapy with EBRT (4-6 weekly cycles of cisplatin) was delivered to all patients with cervical cancer recurrences, and in 3/4 of patients with endometrial cancer. The most common dose fractionation for EBRT was 50 Gy in 25 fractions over 5 weeks (16/19 patients).

The $26 \mathrm{~mm}$ diameter ring was used in 12 patients, $30 \mathrm{~mm}$ in 5 patients, and $34 \mathrm{~mm}$ in 2 patients. The mean $( \pm \mathrm{SD})$ number of needles used was $10( \pm 3)$ needles for each patient. No procedure-related complications were observed. Target coverage was acceptable.

The median $\mathrm{EQD}_{2}$ of $\mathrm{BT}$ dose in the 15 patients with carcinoma cervix recurrences was 18.8 Gy (mean, 20.84 Gy; interquartile range $[\mathrm{IQR}], 8)$, and the median total $\mathrm{EQD}_{2}$ delivered was $68.8 \mathrm{~Gy}$ (mean, 70.43 Gy; IQR, 7.6). The values of $\mathrm{BT}$ and total $\mathrm{EQD}_{2}$ in the 4 patients with endometrial cancer recurrences were median 22.08 Gy (mean, 23.19 Gy; IQR, 7.62), and median 72.08 Gy (mean, 71.6 Gy; IQR, 10.81), respectively.

The mean $2 \mathrm{cc}$ of the bladder, rectum and sigmoid $\mathrm{EBRT}+\mathrm{BT}$ doses $\left(\mathrm{EQD}_{2}\right)$ were $65.38 \mathrm{~Gy}( \pm 7.76), 63.37 \mathrm{~Gy}$ $( \pm 5.52)$, and $57.04 \mathrm{~Gy}( \pm 4.45)$, respectively. At 6-8 weeks response evaluation, 17 patients showed complete response to therapy clinically. With a median follow-up of 20.5 months (IQR, 15.0-26.8), 2-year overall survival was 95\% (95\% CI: 85.2-100.0\%), and 2-year progression-free survival was $79.4 \%$ (95\% CI: $61.0-97.8 \%$ ). 15 patients showed no evidence of disease at last follow-up, 2 patients developed local plus nodal recurrences at 6 and 11 months, 1 patient had a distant metastasis at 4 months, 1 patient showed isolated local recurrence at 12 months (salvaged with re-RT), and 1 patient developed local plus distant recurrence at 11 months, treated with palliative chemotherapy. Late toxicities observed included grade 2 proctitis in 1 patient, grade 1 proctitis in 5 patients, grade 2 urethritis in 1 patient, grade 3 cystitis in 1 patient, and recto-vaginal fistula in 1 patient (with disease controlled). Out of the 19 patients, 5 had a maximum tumor diameter at brachytherapy (post-EBRT) of more than $10 \mathrm{~mm}$ on clinical examination. Complete response at 6 weeks was observed in 2 out of these 5 patients compared to all the 15 patients with tumor diameter at brachytherapy less than $10 \mathrm{~mm}$. The disease recurrence rate was also 6.7 times higher in patients with post-EBRT disease greater than $10 \mathrm{~mm}(p=0.01)$.

\section{Discussion}

Chemotherapy is mainly delivered with palliative intent in the management of local recurrences of gyne- 
A
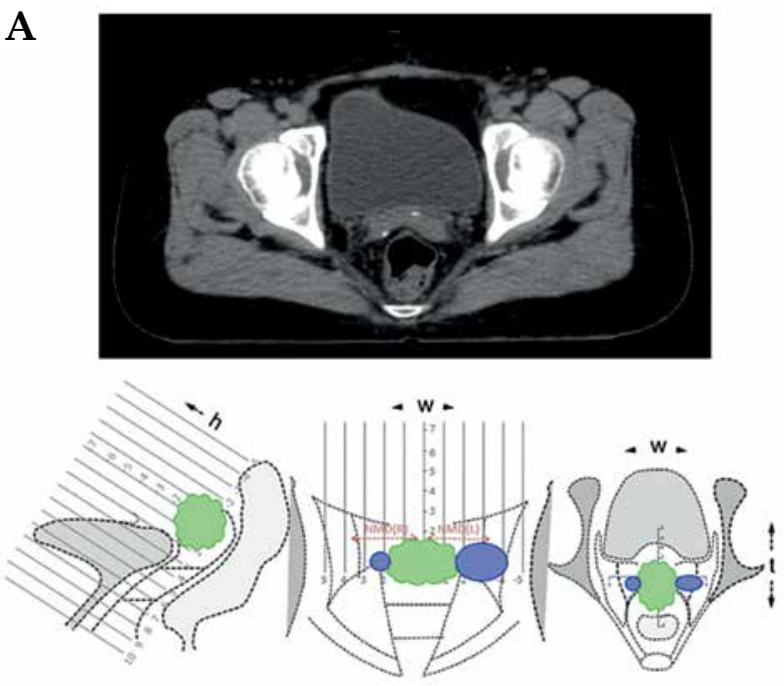

C
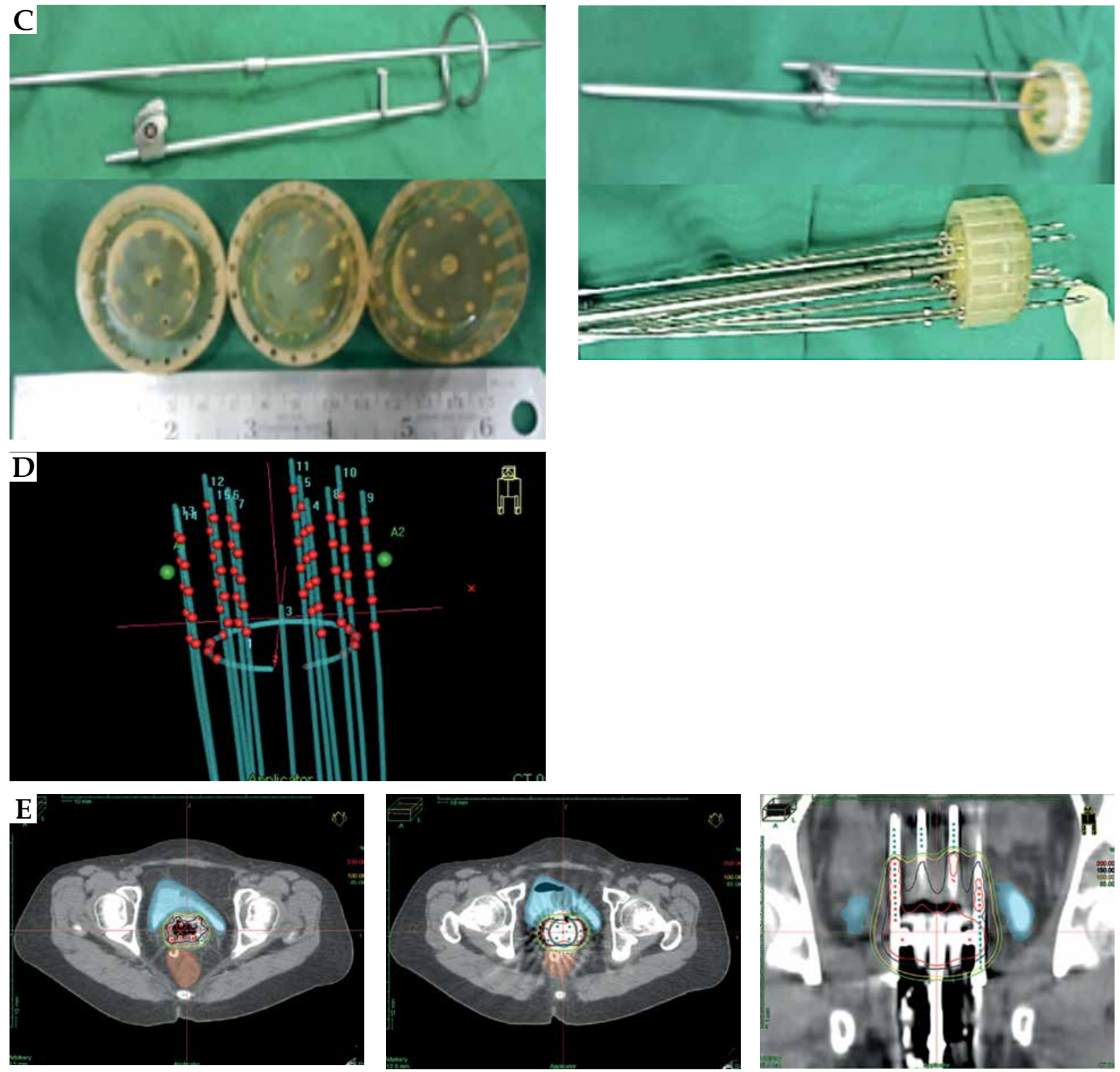

Fig. 2. Example of a patient who underwent modified Houdek application with clinical, radiological, and planning details. A) Tumor at diagnosis with implanted silver markers; B) Tumor at brachytherapy; C) MHVA assembly; D) Reconstruction; E) Treatment planning
B
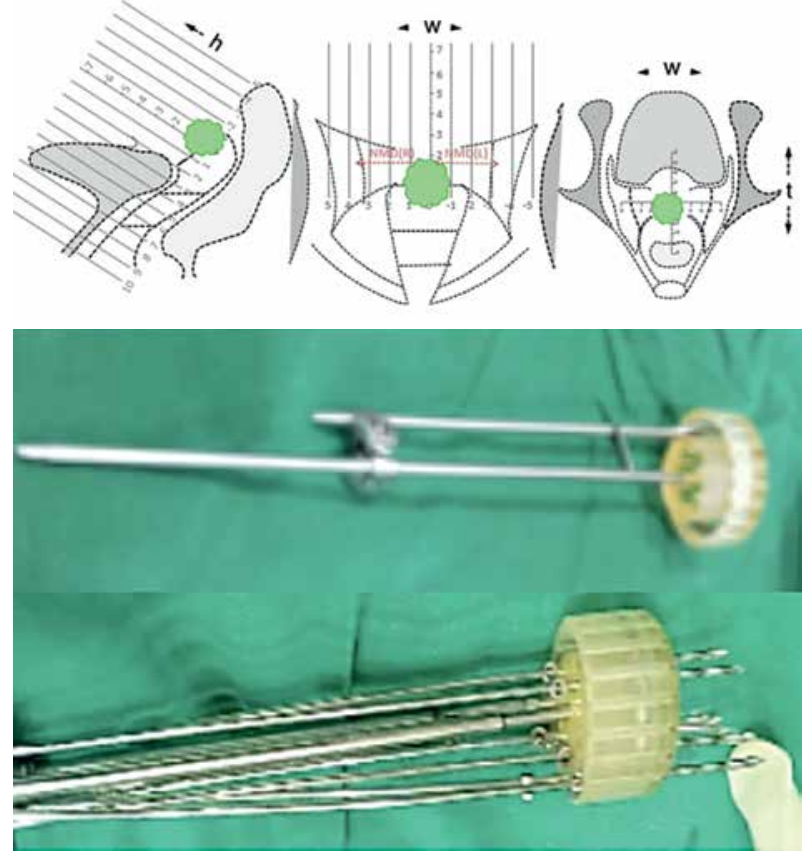
cological cancers, when not amenable to radiotherapy [19]. Vaginal brachytherapy with or without pelvic radiotherapy forms the mainstay of therapy in these patients with the final recommendation depending on prior radiation therapy, thickness of vaginal recurrence, and its' location [4]. The most common applicator employed for vault brachytherapy is the single-channel vaginal cylinder. Fletcher concluded that vaginal cylinder achieved an inadequate dose coverage of the vaginal apex, because it delivered unacceptably high doses to the bladder and rectum [10]. Several dosimetric studies have investigated the benefit of multichannel applicators over single-channel applicators for vaginal brachytherapy $[11,12]$. Multichannel cylinders permit preferential treatment to the vaginal apex or any other part of the vault while allowing relative dose reduction to the bladder and rectum. Nag et al. concluded that while treating vaginal recurrences, intra-cavitary brachytherapy should be restricted to disease with less than $0.5 \mathrm{~cm}$ in thickness [10]. Interstitial perineal template MUPIT, Syed-Neblett, and other templates allow superior and wide lateral coverage of parametrial tissues, particularly when angled holes are utilized, allowing better dose coverage than single- and multichannel intracavitary applicators $[13,14]$. However, it has a distinct physical disadvantage due to an increased distance of needle entry from target volume, leading to crowding of needles superiorly.

The MHVA offers an optimal yet simple alternative to the perineal template in cases where wide lateral coverage is not desired. The application is easy and provides a good dose coverage of the vault apex achieved through adaptable needle placement. The above-mentioned vault applicators are compared in Table 1.

There is an original brachytherapy technique described using a dedicated intra-vaginal template for the treatment of vaginal vault recurrences published in 1998 [13]. The authors described the use of a template, specifically designed to treat tumors located in the vaginal vault in 78 patients with vault recurrence. The local control rate reported was $70 \%$ at 5 years, with $10 \%$ of grade 3 complications. A recurrence diameter of less than $40 \mathrm{~mm}$ correlated significantly with a higher overall survival [13]. Similarly, in our series, the recurrence rate was 6.7 times higher in patients with post-EBRT disease greater than $10 \mathrm{~mm}(p=0.01)$.

Common side-effects reported in the literature after endovaginal BT includes proctitis, cystitis, recto-vaginal fistula, vaginal discharge, dryness, itching, bleeding, fibrosis, telangiectasias, stenosis, short or narrow vagina, and dyspareunia [20]. In our series, one patient developed recto-vaginal fistula as a complication (rectal dose 2 cc, 62.5 Gy). Majority of the patients developed grade 1 proctitis, which resolved with conservative management. Long-term follow-up is needed to assess for vaginal complications.

The main strength of this technique is the ease of procedure as compared to perineal templates and the feasibility of multiple applications. The most important advantage is the placement of applicator closer to the disease rather than at the perineum which is located at least $8-10 \mathrm{~mm}$ away from the target, thus ensuring better stability of application. It is also useful in post-operative patients with a wide vault apex and an M-shaped suture line, where a single-channel applicator would be displaced laterally.

A major limitation is that the smallest available outer diameter of the ring is $26 \mathrm{~mm}$ (the outer diameter of the cap is $40 \mathrm{~mm}$ in all cases, although it is made of a flexible material). In a subset of patients, the superior most part of the vagina and vault apex are narrowed, and the ring would not fit in till the apex, leading to potential air gaps.

This adaptation was made from the original stainless-steel applicator and using steel needles that may create artefacts in planning CT scan obscuring primary target, which makes pre-planning and silver marker placements crucial. Additionally, it is important to pre-plan the length of the needles beyond the ring to avoid bowel perforations and late toxicities. The concept of image-guidance was

Table 1. Comparison of vault applicators

\begin{tabular}{|c|c|c|c|c|}
\hline & $\begin{array}{c}\text { Central vaginal source } \\
\text { (CVS) [11] }\end{array}$ & $\begin{array}{c}\text { Multi-channel vaginal } \\
\text { cylinder }[11,12]\end{array}$ & $\begin{array}{l}\text { Modified Houdek vault } \\
\text { applicator }\end{array}$ & Perineal template $[13,14]$ \\
\hline Description & $\begin{array}{c}\text { Cylinders of different } \\
\text { diameters fitted around } \\
\text { central source }\end{array}$ & $\begin{array}{l}\text { Cylinders of different } \\
\text { diameters with grooves for } \\
\text { peripheral sources fitted } \\
\text { around central source }\end{array}$ & $\begin{array}{l}\text { Short central tandem with } \\
\text { ring fitted with acrylic cap } \\
\text { with concentric holes for } \\
\text { needles }\end{array}$ & $\begin{array}{c}\text { Plastic perineal template } \\
\text { with central hole for } \\
\text { obturator and multiple } \\
\text { straight, and angled holes } \\
\text { for needles }\end{array}$ \\
\hline $\begin{array}{l}\text { Mean rectal } \\
\text { dose }(2 \mathrm{cc})\end{array}$ & $87.0 \%( \pm 10)$ & $72.9 \%( \pm 8.6)$ & $67.11 \%( \pm 8.4)$ & $75.0 \%( \pm 25.0)$ \\
\hline $\begin{array}{l}\text { Mean bladder } \\
\text { dose }(2 \mathrm{cc})\end{array}$ & $71.4 \%( \pm 12.9)$ & $70.0 \%( \pm 11.4)$ & $70.8 \%( \pm 13.2)$ & $32.5 \%( \pm 25.0)$ \\
\hline Advantages & $\begin{array}{l}\text { Easy application and plan- } \\
\text { ning, it can be done under } \\
\text { local anesthesia }\end{array}$ & $\begin{array}{c}\text { Easy application, it can be } \\
\text { done under local anesthe- } \\
\text { sia, differential loading of } \\
\text { peripheral sources }\end{array}$ & $\begin{array}{c}\text { Easy application, good } \\
\text { coverage, variable needle } \\
\text { placement, apex coverage } \\
\text { good }\end{array}$ & $\begin{array}{l}\text { Very versatile applicator, } \\
\text { good coverage of target, } \\
\text { and sparing of OARs }\end{array}$ \\
\hline Limitations & $\begin{array}{l}\text { Apex under coverage, high } \\
\text { bladder and rectum doses }\end{array}$ & $\begin{array}{l}\text { Apex under coverage, } \\
\text { lateral coverage limited }\end{array}$ & Lateral coverage limited & $\begin{array}{l}\text { Difficult procedure re- } \\
\text { quiring expertise, patient } \\
\text { immobilized for } 3 \text { days, } \\
\text { cumbersome }\end{array}$ \\
\hline
\end{tabular}


not fully exploited (target delineation obscured due to the artifacts of steel ring and needles). However, clinical examination findings and silver markers were used as surrogates for optimization. MRI-compatible applicator is the next step forward. This technique, though easy, requires requires core competence of a physician and physicist in planning. When adapting this technique, it is important to conduct a strict commissioning process and quality assurance before implementation for clinical use. While cost-effectiveness of this simple applicator that employs CT-based planning in treating vault recurrences is worth evaluation, it was not the focus of attention in this paper. Other advances for vaginal/vault BT reported in the literature included a novel bivalve vaginal speculum interstitial applicator design and development of 3D-printed intensity-modulated vaginal BT applicators [21, 22].

\section{Conclusions}

High-dose-rate brachytherapy boost using modified Houdek vault applicator for isolated vault cancers post-surgery was feasible and achieved satisfactory dosimetric parameters. The preliminary clinical outcomes and late toxicities are acceptable. This modified BT applicator offers a simple solution for a clinical scenario that is common in developing countries.

\section{Ethical approval}

All procedures performed in studies involving human participants were in accordance with ethical standards of the institutional and/or national research committee, and with the 1964 Helsinki Declaration and its' later amendments or comparable ethical standards.

\section{Informed consent}

Informed consent was obtained from all the participants included in the study.

\section{Disclosure}

The authors report no conflict of interest.

Supplementary table is available on the journal website.

\section{References}

1. Heller S, Kambham N, Smith D et al. Recurrence of gynecologic malignancy at the vaginal vault after hysterectomy. Int J Gynaecol Obstet 1999; 64: 159-162.

2. Sartori E, Pasinetti B, Carrara L et al. Pattern of failure and value of follow-up procedures in endometrial and cervical cancer patients. Gynecol Oncol 2007; 107: S241-S247.

3. Humphrey P, Cornes P, Al-Booz H. Vaginal vault brachytherapy in endometrial cancer: verifying target coverage with image-guided applicator placement. Br J Radiol 2013; 86: 20120428.

4. Kamrava M, BeriwalS, Erickson B et al. American Brachytherapy Society recurrent carcinoma of the endometrium task force patterns of care and review of the literature. Brachytherapy 2017; 16: 1129-1143.
5. Hardarson HA, Heidemann LN, dePont Christensen R et al. Vaginal vault recurrences of endometrial cancer in non-irradiated patients - radiotherapy or surgery. Gynecol Oncol Rep 2015; 11: 26-30.

6. van Wijk FH. Management of recurrent endometrioid endometrial carcinoma: an overview. Int J Gynecol Cancer 2009; 19: 314-320.

7. Gadducci A, Tana R, Cosio S et al. Treatment options in recurrent cervical cancer (Review). Oncol Lett 2010; 1: 3-11.

8. Sekii S, Murakami N, Kato T et al. Outcomes of salvage highdose-rate brachytherapy with or without external beam radiotherapy for isolated vaginal recurrence of endometrial cancer. J Contemp Brachytherapy 2017; 9: 209-215.

9. Sorbe B, Söderström K. Treatment of vaginal recurrences in endometrial carcinoma by high-dose-rate brachytherapy. Anticancer Res 2013; 33: 241-247.

10. Nag S, Erickson B, Parikh S et al. The American Brachytherapy Society recommendations for high-dose-rate brachytherapy for carcinoma of the endometrium. Int J Radiat Oncol Biol Phys 2000; 48: 779-790.

11. Bahadur YA, Constantinescu C, Hassouna AH et al. Single versus multichannel applicator in high-dose-rate vaginal brachytherapy optimized by inverse treatment planning. J Contemp Brachytherapy 2015; 6: 362-370.

12. Demanes DJ, Rege S, Rodriquez RR et al. The use and advantages of a multichannel vaginal cylinder in high-dose-rate brachytherapy. Int J Radiat Oncol Biol Phys 1999; 44: 211-219.

13. Charra C, Roy P, Coquard R et al. Outcome of treatment of upper third vaginal recurrences of cervical and endometrial carcinomas with interstitial brachytherapy. Int J Radiat Oncol Biol Phys 1998; 40: 421-426.

14. Mahantshetty U, Shrivastava S, Kalyani N et al. Template-based high-dose-rate interstitial brachytherapy in gynecologic cancers: a single institutional experience. Brachytherapy 2014; 13: 337-342.

15. Fowler JF. 21 years of biologically effective dose. Br J Radiol 2010; 83: 554-568.

16. Fletcher G. Squamous cell carcinomas. In: Fletcher G (Ed.). Textbook of radiotherapy. Lea \& Febiger, Philadelphia 1973; 653.

17. Hoskin P, Paulsen Hellebus T, Nout R et al. Endometrial cancer 14 The GEC-ESTRO Handbook of Brachytherapy. Part II: Clinical Practice Version 1; 25/04/2016.

18. Cox JD, Stetz J, Pajak TF. Toxicity criteria of the Radiation Therapy Oncology Group (RTOG) and the European Organization for Research and Treatment of Cancer (EORTC). Int J Radiat Oncol Biol Phys 1995; 31: 1341-1246.

19. Pectasides D, Kamposioras K, Papaxoinis G et al. Chemotherapy for recurrent cervical cancer. Cancer Treat Rev 2008; 34: 603-613.

20. Delishaj D, Barcellini A, D'Amico R et al. Vaginal toxicity after high-dose-rate endovaginal brachytherapy: 20 years of results. J Contemp Brachytherapy 2018; 10: 559-566.

21. Kunogi H, Yamaguchi N, Sasai K. Evaluation of a new bivalve vaginal speculum applicator design for gynecologic interstitial brachytherapy. J Contemp Brachytherapy 2020; 12: 27-34.

22. Biltekin F, Akyol HF, Gültekin M, Yildiz F. 3D printer-based novel intensity-modulated vaginal brachytherapy applicator: feasibility study. J Contemp Brachytherapy 2020; 12: 17-26. 